\title{
A comparison of stuttering attitudes among nonstuttering children and parents in Bosnia \& Herzegovina
}

\author{
Mary E. Weidner' ${ }^{1}$ Lejla Junuzovic- Zunic², Kenneth O. St. Louis ${ }^{3}$ \\ ${ }^{1}$ Department of Communication Sciences \& Disorders, Edinboro University, Edinboro, PA, USA; ${ }^{2}$ Department of Speech and Language Pathology and \\ Audiology, University of Tuzla, Tuzla, Bosnia and Herzegovina; ${ }^{3}$ Department of Communication Sciences \& Disorders, West Virginia University, \\ Morgantown, WV, USA
}

Purpose: A growing body of research has addressed children's stuttering attitudes between preschool and upper elementary school. Attitudes among preschoolers and kindergarteners have been reported to be much lower that fifth graders' attitudes, at which time children's attitudes seemingly converge with their parents' attitudes. It has been suggested these observed changes align with children's social and cognitive development and are resistant to the influence of other variables, such as their culture. The purposes of this study were (a) to extend cultural examinations of children's stuttering attitudes in a sample of kindergarteners through sixth graders in Bosnia \& Herzegovina $(B \& H)$, and (b) to compare their attitudes with their parents' attitudes.

Methods: One hundred eighty-six child-parent pairs from B\&H completed translated versions of the child and adult Public Opinion Survey of Human Attributes-Stuttering (POSHAS/Child and POSHA-S). Four child cohorts were examined: (a) kindergarteners, (b) first and second graders, (c) third and fourth graders, and (d) fifth and sixth graders.

Results: Children's stuttering attitudes improved with age, with the youngest cohort holding the most negative attitudes. Parents held consistently more positive attitudes than the children overall, but the oldest children's attitudes were quite similar to the parent group.

Conclusions: Confirming previous research, children's stuttering attitudes progressively improved with age and approached the attitudes of their parents by fifth and sixth grade.

Keywords: Stuttering, Attitudes, Children, Parents, POSHA-S/Child, POSHA-S, Bosnia \& Herzegovina

\section{INTRODUCTION}

\section{Background}

Universally, negative or misinformed stuttering attitudes abound, which often lead to inaccurate stereotyping and/or stigmatization of people who stutter [1]. Attitudes toward any phenomenon are partly formed by what a person believes to be true, as well as how they feel and react toward that phenomenon [2]. In stuttering, attitudinal research has been particularly critical in global efforts to reduce marginalization of people who stutter. St. Louis [3] developed a standard and translatable stuttering attitude instrument, the Public Opinion Survey on Human Attributes-Stuttering (POSHA-S), which provides an impression about respondents' overall beliefs about stuttering and

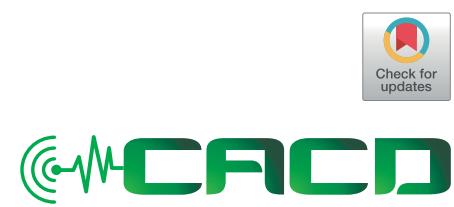

Received: February 15, 2020

Revision: May 9, 2020

Accepted: May 12, 2020

Correspondence:

Mary E. Weidner

Department of Communication Sciences \& Disorders, Human Services Building 247, 215 Scotland Rd., Edinboro, PA 16412, USA

Tel: +814-732-1706

E-mail: mweidner@edinboro.edu

(C) 2020 The Korean Association of SpeechLanguage Pathologists

This is an Open Access article distributed under the terms of the Creative Commons Attribution NonCommercial license (https://creativecommons.org/ licenses/by-nc/4.0/) which permits unrestricted noncommercial use, distribution, and reproduction in any medium, provided the original work is properly cited. 
how they would react toward a person who stutters. A large coalition of international collaborators contributed to the growth of the POSHA-S database, which includes 16,195 respondents from 46 countries around the world. This undertaking has permitted the identification of variables that are particularly influential on stuttering attitudes, which has led to collective efforts to improve public attitudes [4]. Even though reports of stigmatizing attitudes are ubiquitous [5-9], several cross-cultural studies have pointed to notable between country differences. In a seminal text on the topic, St. Louis [10] advanced the probable effect of one's geography and/or culture on stuttering attitudes, with better attitudes among persons from North America and Western Europe, followed by Eastern Europe, the Middle East, Africa, and Asia. Recently, a largescale study involving over one thousand adults from several European countries (i.e., Bosnia \& Herzegovina, Italy, Norway, Germany, Ireland, and England) found that this assumption in Western Europe was not entirely true. The study found (a) similar attitudes among respondents from different regions of the same country but (b) more pronounced attitudinal homogeneity among respondents from the same country compared to different countries, especially differences between Scandinavian countries and Italy [11]. Although not fully elucidated, the authors posited "factors related to one's nationality as the most likely predictors of observed differences in measured attitudes toward stuttering" [11].

\section{Children stuttering attitudes}

In efforts to broaden epidemiological efforts to be inclusive of younger respondents, Weidner \& St. Louis [12] developed the POSHA-S/Child. As explained in the methodology section, the instrument closely parallels the adult version, but can be used with respondents as young as 3 years of age. Since its inception, the instrument has permitted attitude comparisons between cohorts of children and adults [13], and is sensitive to attitude change following an intervention [14]. To date, research using the POSHA-S/Child has provided information about the nature of children's stuttering attitudes and plausible explanations about why they change over the course of one's early childhood. In contrast to the well-established adult literature, children's stuttering attitudes have been suggested to be resistant to external cultural influences and more influenced by internal (i.e., developmental) processes, which is consistent with literature in developmental psychology [15].

The first published study using the POSHA-S/Child involved preschool and kindergarten children from a Mid-At- lantic region of the United States. Results suggested that stuttering awareness and negative attitudes emerge during the preschool years [16], which supported previous research using other methodologies [17-19]. That study was among the first to suggest that preschoolers' attitudes are actually worse than those held by older children - and both groups are comparatively lower than adults' attitudes. In a similar study carried out in Turkey using a translated version of the POSHA-S/ Child, preschoolers held as equally poor stuttering attitudes as the American cohort [20]. This was surprising, given that previous research reported nearly identical stuttering attitudes among sixth-grade Turkish children and their family members [21]. Although those early studies provided evidence for the emergence of stuttering attitudes at a young age, they could not explain the suspected attitude changes between early and late childhood or how children's attitudes compare to the adult majority.

To address that need, Glover, St. Louis, \& Weidner [22] measured the stuttering attitudes of preschool through fifth grade children as well as their parents. A total of 150 child-parent pairs participated $(N=300)$ representing: preschool $(n=46)$, kindergarten ( $n=36)$, first grade $(n=42)$, second grade $(n=38)$, third grade $(n=48)$, fourth grade $(n=42)$, and fifth grade $(n=48)$. As measured on the adult and child versions of the POSHA-S, attitude trends revealed a generally upward trajectory of attitudes with age, with a dip around second grade. Parents held more positive attitudes, which were not influenced by the grade of their child. Of all parent-child Overall Stuttering Score comparisons, the preschool-parent pairs were the most dissimilar, differing by 33 units. This is compared to fifth grade-parent pairs, which differed by only 7 units.

Results from Glover et al. [22] suggested that children's stuttering attitudes significantly change between early and middle childhood, whereas parents' stuttering attitudes remain stable. The authors posited that children's stuttering attitudes may emerge as a byproduct of social cognitive skills and gradually align with their prevailing culture. As such, young children are more likely to have stuttering attitudes that diverge from their parents' attitudes as compared to slightly older children. In order to substantiate these observations, the authors urged for replications of the study among multicultural samples.

\section{Cross-cultural extensions}

Theories about the emergence of stuttering attitudes in young children intrigued many POSHA-S collaborators, especially those who conducted attitude research in adults. The second 
author, who is from Bosnia \& Herzegovina (B\&H), indicated a replication of the Glover et al. [22] study in B\&H would provide useful contributions to understanding the evolution of attitudes among young children and the possible parental influences on their attitudes.

Based on its location in the west part of the Balkan Peninsula in southeastern Europe, B\&H has been a crossroads of diverse populations dating back to the Neolithic age, which has fostered a rich culture. It currently has a population of over 3.5 million and, despite a turbulent history, has made strides to stabilize its [23]. Islam, Eastern Orthodoxy, and Catholicism are the dominant religions practiced by $44 \%, 31 \%$, and $15 \%$ of the population, respectively. The national language has three distinct dialects including Bosnian, Croatian, and Serb, which are very similar in spoken form. The primary school system is similar to the public-school system in America. During the first four years, children are in one classroom and have one teacher for all subjects. From fifth grade onwards, students are taught separate subjects by different teachers [24]. In contrast to American practices, however, children with special needs are generally serviced in designated special education schools and centers, not in the general education setting. The country is making a concerted effort to reform its inclusion practices but have a lack of trained special educators to do so effectively [25].

Bosnia \& Herzegovina emerged as a feasible country in which to replicate the Glover et al. [22] studies for two primary reasons. First, previous stuttering attitude research in B\&H has provided a strong foundation for continued investigations and cross-cultural comparisons. The aforementioned study by St. Louis, Sønsterud et al. [11], adults in B\&H showed internally consistent attitudes throughout three distinct regions of the country, each representing a different majority religious affiliation. Overall, attitudes among B\&H adults were about the same or slightly better than median scores from the $P O$ SHA-S database. Second, B\&H has a distinct cultural identity relative to its social and economic history, educational practices, as well as language, religious, racial diversity. The unique culture of $\mathrm{B} \& \mathrm{H}$, coupled with the previous stuttering attitude research in the region, allow researchers to better understand the role of culture versus other factors, such as social cognitive development, on stuttering attitudes.

\section{Purpose}

The purposes of this study were to examine the differences of stuttering attitudes among children from $\mathrm{B} \& \mathrm{H}$ across different grade levels and compare their attitudes to those of their parents. Bearing on previous research theorizing children's stuttering attitudes are resistant to culture [20] and that attitudes improve throughout early childhood [22], we hypothesized (a) children's attitudes would follow an upward trajectory with age, (b) younger children would hold significantly worse attitudes than their parents, and (c) older children would hold similar attitudes to their parents.

\section{METHODS}

\section{Instruments}

The children filled out the Public Opinion Survey on Human Attributes-Stuttering (POSHA-S/Child), and the parents filled out the adult version of the POSHA-S, with the addition of an informational section relative to their child and added anchor traits, described below. The POSHA-S follows a long line of research dating back two decades and has been used extensively across the world. Psychometric properties (i.e., test-retest reliability, internal consistency, construct, and concurrent validity), translatability, and ease of use have been confirmed in dozens of studies, which are summarized by St. Louis [10,26]. Weidner and St. Louis [12] developed the POSHA-S/Child, which has since been used to measure children's stuttering attitudes [16], detect change in attitudes following an intervention [14], and compare child and parent attitudes using the corresponding versions of the POSHA-S [11,22]. The POSHA-S/Child has been shown to hold satisfactory test-retest reliability [27] and can be administered orally or face-to-face to 9 to 11 year-olds [28].

The POSHA-S and POSHA-S/Child follow a similar scoring framework, with individual items averaging into component scores categorized into the Beliefs (BEL) or Self Reactions (SR) Subscores. The Subscores are averaged to generate an Overall Stuttering Score (OSS). On both instruments, scores are interpreted on a -100 to +100 continuum, with higher values corresponding to more positive or informed stuttering attitudes and " 0 " as neutral (see St. Louis [26] for a detailed description of the scoring system). Each instrument also has a demographic section, which provides information about respondents' sex, age, health and abilities, relative income, education level, and familiarity with/exposure to various human attributes (i.e., stuttering, wheelchair-use, obesity). Parent respondents complete the demographic section for their children.

There are a few, but important, differences between the adult and child instruments worth mentioning. First, although 
they share 28 similar items, the wording is slightly different in order to make the language understandable for child respondents. For example, "genetics" on the adult version is worded "came from their mom or dad when they were born" on the child version. Second, the child version provides respondents with a video example of stuttering (as demonstrated by customized cartoon characters), followed by a definition of stuttering. The absence of a definition on the adult version makes no differences in results [11]. Third, each instrument provides a reference point for stuttering attitudes using other human traits. In order to compare the child and parent responses, the anchor traits "obesity" and "wheelchair use" were selected. Parents rate their preferences about the stuttering, wheelchair use, and obesity using a Likert scale and children are shown visual depictions (i.e., line drawings) of the traits in counterbalanced pairs, and asked, "which one would you rather be?" Rank-ordered preferences of the three traits are generated for both the parent and child groups.

A previously translated POSHA-S into Bosnian-CroatianSerbian was used for adult respondents [11] and the child survey was translated into Bosnian-Croatian-Serbian for this study. Translation procedures followed that of previous $P O$ SHA-S studies, in which the English version was translated to Bosnian-Croatian-Serbian, and then back-translated into English by persons fluent in those languages. The video example of stuttering was also translated into Bosnian-CroatianSerbian. It featured the same cartoon images, topic of discourse, and frequency and type of stuttered speech as that of the English version.

\section{Design}

The second author obtained the permissions for human subject research through the primary and kindergarten school sites. Child-parent pairs were recruited using convenience sampling techniques at various primary schools throughout the city of Tuzla, Bosnia \& Herzegovina. The grades were combined into four cohorts to represent children in kindergarten, early, middle, and upper elementary-aged children and their parents.

The second author and a research assistant from the University of Tuzla gave hard copies of the POSHA-S to classroom teachers, who then distributed the surveys to parents. The parents returned completed forms to the school, which the researchers collected. Trained graduate students conducted the POSHA-S/Child orally to the two younger cohorts and recorded children's responses on a hard copy of the survey. The older children completed pencil-and-paper survey in the school setting. A recent study confirmed no differences between oral and face-to-face delivery [28].

\section{Analysis of results}

Descriptive data for items, components, Subscores, and the Overall Stuttering Score (OSS) were analyzed for both the child and parent groups. Within and between group differences for summary scores (i.e., components, Subscores, and OSS) were calculated using independent t-tests. Cohen's d effect sizes for significant differences were also reported. To account for the number of comparisons and thereby control for Type 1 error, an adjusted significance level of $p \leq 0.0047$ $(.05 / 12)$ was used.

\section{RESULTS}

\section{Children's demographics}

One-hundred eighty-six nonstuttering children participated in the study. Children with parental consent, gave assent, and who demonstrated the ability to reliably comprehend and respond to the survey questions were included in the study. The latter criterion was determined via a combination of teacher and parental report. Children were not excluded on the basis of sex, socio-economic status, or race. Although stuttering was not an exclusionary criterion, based on parent report, none of the children in the current study stuttered.

Children's demographic information is summarized in Table 1 . By grade, there were 61 kindergarteners, 24 first graders, 22 second graders, 19 third graders, 20 fourth graders, 15 fifth graders, and 25 sixth graders. As noted, however, these data were combined into four cohorts: kindergarteners $(n=61)$, first and second graders $(n=46)$, third and fourth graders ( $n=39)$, and fifth and sixth graders $(n=40)$. The average age of the children was 8.1 years (range 3.6 to 12.8 years). Slightly more females than males participated ( $57 \%$ compared to $43 \%$ ). There was a steady increase in multilingualism, ranging from $12 \%$ of kindergarteners to $76 \%$ of sixth graders. Parents completed a short profile about their child's health, abilities, and if their child was or knew anyone who is obese, a wheelchair user, or a person who stutters. As interpreted on the -100 to +100 scale, the children reportedly had overall good physical health (91), mental health (95), ability to learn (94), and ability to speak (89). A minority of children were obese (6\%), and none of the children stuttered or used a wheelchair. Children's reported exposure to those traits was much higher with 
Table 1. Demographic information of children, reported by parents, organized by the four cohorts (Columns 1-4) and combined (Column 5) as well as parents' demographic information (Column 6)

\begin{tabular}{|c|c|c|c|c|c|c|}
\hline Demographic variable & Kindergarten & 1st \& 2nd grades & 3rd \& 4th grades & 5 th $\&$ 6th grades & Children all & Parents al \\
\hline Column & 1 & 2 & 3 & 4 & 5 & 6 \\
\hline Number & 61 & 46 & 39 & 40 & 186 & 186 \\
\hline \multicolumn{7}{|l|}{ Descriptors } \\
\hline Age (yr) & 5.2 & 7.5 & 9.5 & 11.6 & 8.1 & 38.4 \\
\hline Education (yr) & - & - & - & - & - & 14.2 \\
\hline Male & $38 \%$ & $50 \%$ & $49 \%$ & $38 \%$ & $44 \%$ & $18 \%$ \\
\hline Female & $62 \%$ & $50 \%$ & $51 \%$ & $62 \%$ & $56 \%$ & $82 \%$ \\
\hline Multilingual & $11 \%$ & $33 \%$ & $41 \%$ & $70 \%$ & $41 \%$ & $52 \%$ \\
\hline$\geq 1$ Sibling & $54 \%$ & $74 \%$ & $74 \%$ & $80 \%$ & $49 \%$ & - \\
\hline Regular daycare & $75 \%$ & $4 \%$ & $0 \%$ & $0 \%$ & $49 \%$ & - \\
\hline Regular school & $0 \%$ & $100 \%$ & $100 \%$ & $100 \%$ & $75 \%$ & - \\
\hline \multicolumn{7}{|l|}{ Identification } \\
\hline Obese & $3 \%$ & $2 \%$ & $8 \%$ & $13 \%$ & $7 \%$ & $6 \%$ \\
\hline Wheelchair & $0 \%$ & $0 \%$ & $0 \%$ & $0 \%$ & $0 \%$ & $0 \%$ \\
\hline Stuttering & $0 \%$ & $0 \%$ & $0 \%$ & $0 \%$ & $0 \%$ & $0 \%$ \\
\hline Intelligent & - & - & - & - & - & $17 \%$ \\
\hline Left handed & - & - & - & - & - & $3 \%$ \\
\hline \multicolumn{7}{|l|}{ No persons known... } \\
\hline Obese & $33 \%$ & $20 \%$ & $3 \%$ & $13 \%$ & $17 \%$ & $8 \%$ \\
\hline Wheelchair & $75 \%$ & $52 \%$ & $56 \%$ & $40 \%$ & $56 \%$ & $40 \%$ \\
\hline Stuttering (parent report) & $54 \%$ & $56 \%$ & $36 \%$ & $38 \%$ & $46 \%$ & $21 \%$ \\
\hline Intelligent & - & - & - & - & - & $2 \%$ \\
\hline Left handed & - & - & - & - & - & $5 \%$ \\
\hline \multicolumn{7}{|l|}{ Health \& abilities $(-100-+100)$} \\
\hline Physical health & 92 & 95 & 81 & 94 & 90 & 65 \\
\hline Mental health & 95 & 99 & 86 & 99 & 95 & 84 \\
\hline Ability to learn & 96 & 97 & 87 & 94 & 72 & 78 \\
\hline Ability to speak & 84 & 93 & 86 & 95 & 90 & 88 \\
\hline \multicolumn{7}{|l|}{ Life priorities } \\
\hline Be safe/secure & - & - & - & - & - & 88 \\
\hline Be free & - & - & - & - & - & 69 \\
\hline Spend time alone & - & - & - & - & - & 27 \\
\hline Attend social events & - & - & - & - & - & 18 \\
\hline Imagine new things & - & - & - & - & - & 31 \\
\hline Help less fortunate & - & - & - & - & - & 70 \\
\hline Have exciting experiences & - & - & - & - & - & -34 \\
\hline Practice my religion & - & - & - & - & - & 46 \\
\hline Earn money & - & - & - & - & - & 76 \\
\hline Do job/duty & - & - & - & - & - & 91 \\
\hline Get things done & - & - & - & - & - & 89 \\
\hline Solve big problems & - & - & - & - & - & 82 \\
\hline \multicolumn{7}{|l|}{ Impression } \\
\hline Obese & - & - & - & - & - & 3 \\
\hline Wheelchair & - & - & - & - & - & 41 \\
\hline Stuttering & - & - & - & - & - & 26 \\
\hline \multicolumn{7}{|l|}{ Want/have } \\
\hline Obese & - & - & - & - & - & -72 \\
\hline Wheelchair & - & - & - & - & - & -70 \\
\hline Stuttering & - & - & - & - & - & -59 \\
\hline \multicolumn{7}{|l|}{ Amount known } \\
\hline Obese & - & - & - & - & - & 14 \\
\hline Wheelchair & - & - & - & - & - & -2 \\
\hline Stuttering & - & - & - & - & - & -9 \\
\hline
\end{tabular}


$19 \%$ knowing a person who was obese, $58 \%$ knowing a person in a wheelchair, and $47 \%$ knowing a person who stuttered.

\section{Parent's demographics}

One parent of each child filled out a questionnaire; therefore, the sample sizes were identical $(n=186)$. The average years of schooling for all parents was 14.1 years, which differed only slightly by grade of the child (range 13.3 years for parents of sixth graders to 15.2 years for parents of second graders). Most respondents were mothers $(82 \%)$, nearly all were married (99\%), and all were Caucasian. Further, almost three-fourths worked (76\%) and were multilingual (76\%). Religious practices primarily included Islam (45\%) and Catholicism (27\%). Twenty-three percent did not report their religion. Self-reported relative income scores, interpreted on the -100 to 100 scale, revealed a slightly lower-than average income of -8 as compared to the median POSHA-S database income of +1 (circa January, 2020). Overall, parents reported good health and abilities. Parents' demographic information is summarized in Table 1.

\section{Children attitudes}

Figure 1 depicts the POSHA-S/Child summary scores with better or more informed attitudes toward the periphery. As shown, children's stuttering attitudes steadily improved with age. Across the four cohorts, Overall Stuttering scores were: -6 (kindergarteners), -2 (first and second graders), 9 (third and fourth graders), and 19 (fifth and sixth graders). Significant differences existed between the kindergarten and third/fourth graders ( $p=0.00008)$, the kindergarten and fifth/sixth graders $(p<0.00001)$, and the first/second graders and fifth/sixth graders $(p<0.00001)$. The Subscores and many components also revealed progressively higher scores across cohorts for Self Reactions (including the Traits/Personality, Help From, and Potential components) and Beliefs (including the Accommodating/Helping component). All POSHA-S/Child items and summary score means are detailed in Appendix A.

\section{Parent attitudes}

Parents' Overall Stuttering Score was 26, ranging from 23 (parents of third and fourth graders) to 30 (parents of kindergarteners). Stuttering Beliefs and Self Reactions were 35 and 17, respectively. Although parents of kindergarteners consistently held the most positive attitudes, there were no significant differences between the parents based on their children's age. Appendix A outlines all parent ratings on the POSHA-S.

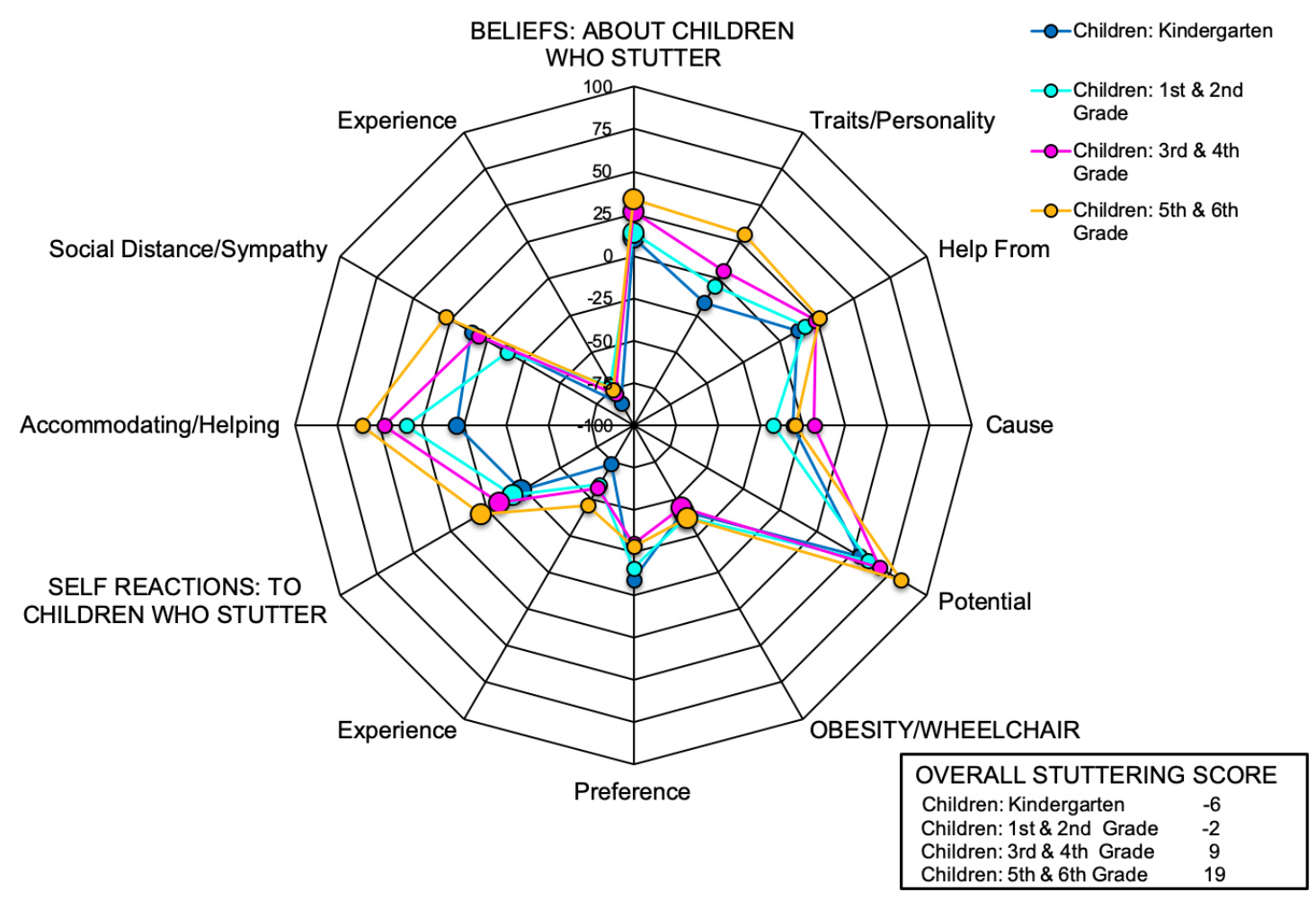

Figure 1. Mean POSHA-S/Child Summary Scores for 186 children in 4 cohorts. 


\section{Child-parent comparative data}

With few exceptions, parents consistently held higher stuttering attitudes compared to the child group. Parent vs. child comparisons revealed significant differences relative to OSS (child $=3$, parent $=26, p<0.00001$ ), Beliefs (child $=19$, parent $=35, p<0.00001$ ), and Self Reactions (child $=-13$, parent $=17, p<0.00001$ ), and the effect sizes were large. With one exception (i.e., stuttering should be helped by), parents' attitudes were more positive or informed than the children's attitudes to a significant degree. Table 2 shows all comparisons between the child and parent groups for comparable items. Independent t-tests were utilized to analyze group differences, with a significance level of $p<0.00417$.

Comparisons by cohort revealed a clear trend for children's OSSs steadily approaching those of their parents. For example, the youngest child cohort (i.e., kindergarteners) significantly different from the parents, (youngest child cohort $=-6$, parent $=26, p<0.00001$ ), but the oldest child cohort (i.e., fifth/ sixth graders) did not significantly differ (oldest child cohort $=19$, parent $=26, p=0.092$ ). Figure 2 represents the trajec-

Table 2. POSHA-S means (and standard deviations) for all ratings, and t-test values, t-test probabilities, and effect sizes for summary scores between 186 children and 186 parents

\begin{tabular}{|c|c|c|c|c|c|}
\hline POSHA-S Variable & Children $(n=186)$ & Parents $(n=186)$ & t-Test Values & t-Test Proba-bility & Cohen's $d$ Effect Size \\
\hline Overall stuttering score & $3(21.9)$ & $26(19.3)$ & -12.04 & $<0.00001$ & 1.114 \\
\hline Beliefs & $19(27.3)$ & $35(27.3)$ & -6.87 & $<0.00001$ & 0.586 \\
\hline Traits/personality & $1(55.2)$ & $39(67.6)$ & -4.89 & $<0.00001$ & 0.616 \\
\hline Helped from & $19(40.0)$ & $-1(44.9)$ & 1.32 & 0.187 & 0.470 \\
\hline Potential & $64(47.2)$ & $72(31.6)$ & -3.05 & 0.002 & 0.199 \\
\hline Self reactions & $-13(23.9)$ & $17(24.9)$ & -12.66 & $<0.00001$ & 1.229 \\
\hline Accommodating/helping & $33(40.4)$ & $54(31.9)$ & -7.01 & $<0.00001$ & 0.577 \\
\hline Social distance/sympathy & $7(45.7)$ & $35(38.8)$ & -6.30 & $<0.00001$ & 0.661 \\
\hline Obesity/wheelchair use & $-40(23.3)$ & $-14(32.4)$ & -9.96 & $<0.00001$ & 0.921 \\
\hline
\end{tabular}

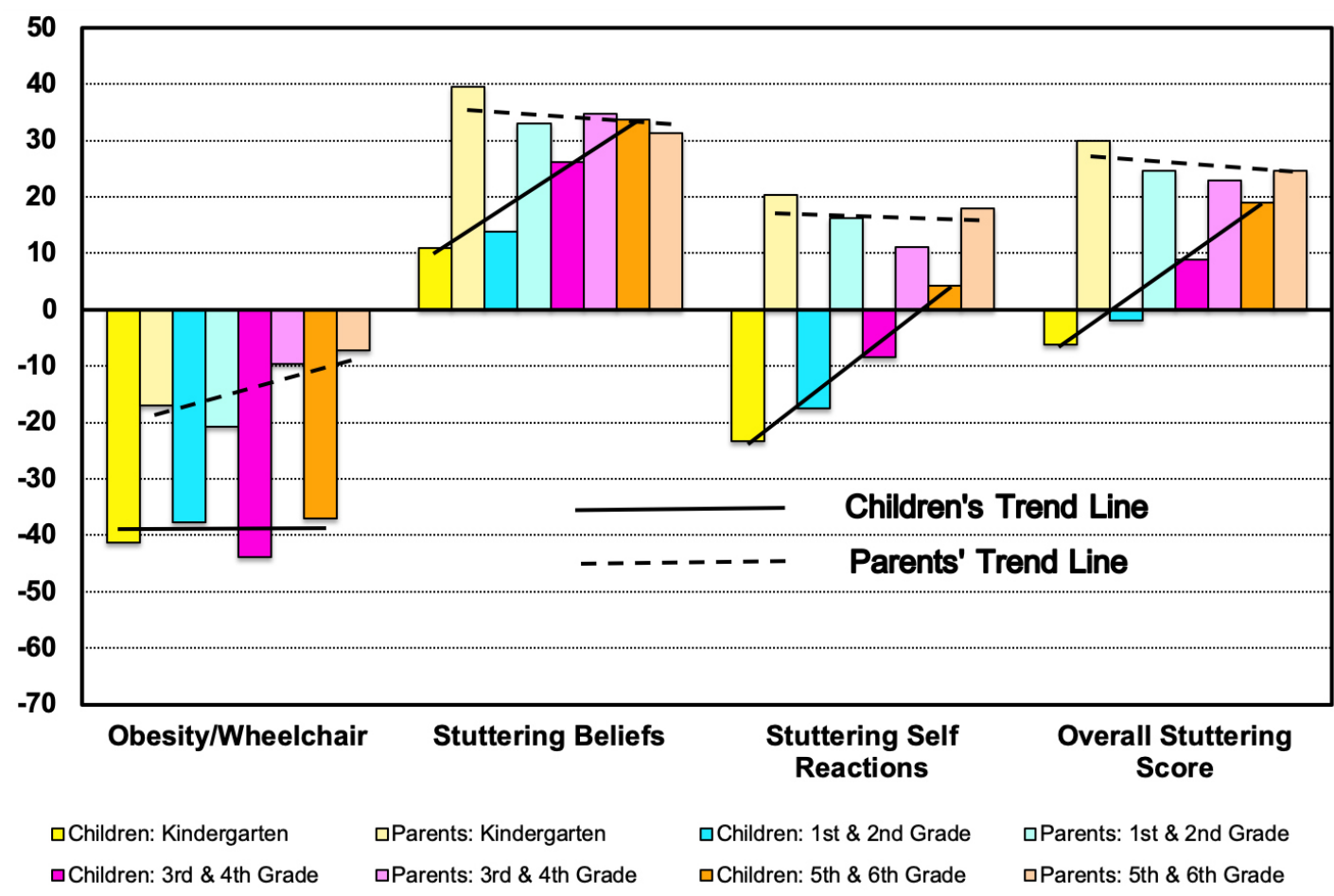

Figure 2. Child versus parent means for POSHA-S and POSHA-S/Child Overall Stuttering Score and Subscores as well as trends according to children's grade levels. 
tories of children and parent attitudes. The darker colored bars represent the children's scores by cohort, which are contrasted to parent scores by cohort in a lighter shade of the same color. As can be seen on the solid black trend line, it is clear that children's stuttering attitudes increase predictably with age, compared to parent attitudes which are more stable. One exception is the Obesity/Wheelchair Subscore, in which the child cohorts reported similar - and markedly lower attitudes compared to the parent group.

\section{DISCUSSION}

This study sought to compare the stuttering attitudes of children and their parents from Bosnia \& Herzegovina (B\&H). Children were grouped into one of four cohorts: kindergarten, early elementary (i.e., first and second graders), middle elementary (third and fourth graders), and upper elementary (i.e., fifth and sixth graders). The children and parents completed respective versions of the POSHA-S, and results between the groups were compared and further analyzed based on the age of the child. Overall, children's attitudes improved with age, with the youngest children holding the worst stuttering attitudes, and the oldest children holding the most positive or informed attitudes. Compared to the parent group, the youngest cohort held significantly worse attitudes, but such differences were not observed between parents and the oldest cohort.

\section{Changes in children's stuttering attitudes}

As a whole, the four cohorts held relatively positive attitudes related to the potential of a person who stutters to make friends, make good choices, and have any job as an adult. On the other hand, however, the four cohorts generally held unfavorable attitudes about the traits of people who stutter and had limited knowledge about stuttering causes or how to sensitively react to a person who stutters. Even at the upper elementary level, children maintained stereotypical beliefs that people who stutter are nervous or shy and "unable to talk well."

In examination of the children by cohort, important differences emerged, thus upholding our first hypothesis that children's attitudes would steadily increase with age. The Self Reaction, Beliefs, and Overall Stuttering Scores increased across all four cohorts, with OSS improving 4 units between kindergarten and early elementary, 7 units between early and middle elementary, and 10 units between middle and upper elementary. That the youngest cohort held the worst attitudes overall is not surprising. In fact, it upholds previous stuttering research which suggested cognitive and social development may explain attitudinal differences between younger and older children [16,20,22]. Differences between the youngest and oldest cohorts are particularly salient. Between kindergarten and upper elementary, children's OSS increased to a significant degree (+25 units, $p<0.00001)$, and all component scores increased. Older children were less likely to believe that children who stutter are at fault for their stuttering and had more sensitive Self Reactions when talking with a person who stutters. For example, older children were less likely to say, "slow down" or "finish the words [of a person who stutters]." This can likely be contributed to the fact that older children are more mature in the domains of social cognition and, by parent report, had more frequent experiences with/exposure to people who stutter. In examination of the children as a group and by cohort, we advance that, although attitudes improve with age, evidence of a negative stuttering stereotype is evident across elementary-aged children in $\mathrm{B} \& \mathrm{H}$.

\section{Child and parent comparisons}

Overall, parents held better attitudes than the children in each of the cohorts; however, those differences were more pronounced between the parents and youngest children. Significant differences existed between the parent and kindergarteners for Overall Stuttering Score (kindergarteners $=-6$, parents $=26, p<0.00001$ ), Beliefs Subscore (kindergarteners $=11$, parents $=35, p<0.00001$ ), and Self Reactions Subscore (kindergarteners $=-23$, parents $=17, p<0.00001$ ). The gap between parent-child attitude scores narrowed with older children [21, 22]. Compared to the kindergarten, early, and middle elementary cohorts, attitudes of upper elementary children most closely aligned with parent attitudes. Specifically, there were no significant differences between the groups' Overall Stuttering Score (upper elementary $=19$, parents $=26$ ) and Beliefs Subscore (upper elementary $=34$, parents $=35$ ). However, a significant difference existed for the Self Reactions Subscore (upper elementary $=4$, parents $=17, p<0.002$ ).

\section{Attitude comparisons between B\&H and US samples}

This study is a replication of Glover et al. [22], who investigated the stuttering attitudes of 150 preschool through fifth grade American children and their parents. As a whole, attitudes of the American children held more positive stuttering attitudes than the B\&H children. This was true for OSS (American $=11, B \& H=3$ ), Self Reactions (American $=-2, B \& H=-13$ ), and Beliefs (American=24, B\&H=19) and all but one compo- 
nent score (i.e., Traits). This pattern was also observed for each cohort of children (i.e., preschool/kindergarten, early, middle, and upper elementary). At this time, it is premature to determine why US children held slightly elevated attitudes. One might advance that the special educational services and inclusivity practices in the US are more established compared to $\mathrm{B} \& \mathrm{H}$ [25]. Thus, the US sample may have had more exposure to peers with diverse abilities, but this cannot be confidently supported based on the results from the current study. Future examinations might consider the influence on children's exposure to disabilities and differences in general, not just the traits investigated in this study (i.e., stuttering, obesity, and wheelchair use).

It should be explained that children in the B\&H kindergarten cohort also include, by American classifications, preschool-aged children. Therefore, the mean age in the American preschool and kindergarten groups combined was similar to the B\&H kindergarten sample (i.e., 5.18 years and 5.21 years, respectively). In addition, the American sample did not include sixth grade children, thus slightly elevating the mean age of the oldest cohort in the B\&H group (American $=10.5$ years, $B \& H=11.6$ years). Despite lower attitudes overall, the B\&H children showed a similar upward trajectory of attitudes with age. American children's attitudes converged with their parents at a slightly younger age (i.e., fourth and fifth grade), opposed to similar attitudes among B\&H parents and sixth graders. In a study of Turkish children and their families, Özdemir and colleagues [21] also identified convergence of child and parent attitudes around sixth grade. It must be remembered that in that study, only the POSHA-S was administered. More research will need to be carried out to determine whether or not sixth grade is a consistent "point of attitudinal convergence" in other cultures as well. Interestingly, American children's ratings for Obesity/Wheelchair worsened with age, while they remained fairly stable across the B\&H cohorts. Despite this finding, Obesity/Wheelchair ratings were quite low in both groups (American $=-37, \mathrm{~B} \& \mathrm{H}=-40$ ).

Stuttering attitudes of neither the American nor B\&H parent groups were influenced by the age of their children. Unlike the child groups in which the American children held slightly better attitudes, attitudes between American and B\&H parents were comparable for OSS (American $=25, \mathrm{~B} \& \mathrm{H}=26$ ), Self Reactions (American =8, B\&H =17), and Beliefs (Ameri$\mathrm{can}=42, \mathrm{~B} \& \mathrm{H}=35)$. That American children - but not American parents - held slightly elevated attitudes compared to the respective $\mathrm{B} \& \mathrm{H}$ groups is unclear. Results such as these should continue to be investigated with additional diverse samples to further examine whether or not children's stuttering attitudes are generally higher in some cultures.

\section{Limitations and future research}

Although these results reflect a robust sample of children from $\mathrm{B} \& \mathrm{H}$ and their families, the sample is restricted to one geographic region of $\mathrm{B} \& \mathrm{H}$. This is particularly important, given $\mathrm{B} \& \mathrm{H}$ is comprised of three distinct regions characterized by differences in spoken dialect and religious practices, even though small differences were observed among them for adults [11]. Accordingly, caution should be exercised in generalizing our results to all regions of the country.

At this time, this and previous studies uphold the notion that children's stuttering attitudes improve in conjunction with their social and cognitive [16,20-22]. Improvements in social awareness, perspective taking, and a more diverse social experiences might factor into children's understanding about stuttering and people who stutter, which has been posited in related research on stigma development [15]. However, it is still premature to confidently advance such claims. It will be important for future research to consider how the results from this and the preceding Glover et al. [22] study compare to samples in different cultures or regions.

The continued expansion of this line of research will not only contribute to epidemiological advancements in this area but will help to identify populations at "high risk" for holding misinformed or negative attitudes, so that appropriate and swift attitudinal improvement efforts can take place. Based on this and previous research, it seems that preschool and kindergarten aged children are among those at "high risk" for negative stuttering attitudes, thus potentially warrant priority in educational efforts to mitigate negative stuttering attitudes. Weidner et al. [14] reported an effective stuttering educational program for young children called the InterACT program [29], which might be considered in attitude betterment efforts. Educational programs, coupled with the collective - and persistent - efforts of researchers and practitioners, will be the necessary elements to ultimately improve children's stuttering attitudes and promote a more tolerant and accepting communication environment for people who stutter.

\section{REFERENCES}

1. Boyle MP, Blood GW. Stigma and stuttering: conceptualizations, applications, and coping. In: St. Louis KO, editor. Stuttering meets 
stereotype, stigma, and discrimination: an overview of attitude research. Morgantown, WV: West Virginia University Press; 2015. p. 43-70.

2. Triandis H. Attitudes and attitude change. New York, NY: Wiley; 1971.

3. St Louis KO. The public opinion survey of human attributes-Stuttering (POSHA-S): summary framework and empirical comparisons. Journal of Fluency Disorders. 2011;36:256-261.

4. St. Louis KO, Węsierska K, Przepiórka A, Błachnio A, Beucher C, Abdalla F, et al. Success in changing stuttering attitudes: A retrospective study of 29 intervention samples. Journal of Communication Disorders; 2020. https://doi.org/10.1016/j.jcomdis.2019.105972.

5. Al-Khaledi M, Lincoln M, McCabe P, Packman A, Alshatti T. The attitudes knowledge and beliefs of Arab parents in Kuwait about stuttering. Journal of Fluency Disorders. 2009;34:44-59.

6. Błachnio A, Przepiórka A, St Louis KO, Wesierska K, Wesierska M. Social attitudes towards stuttering in Poland-An overview of research using the POSHA-S. In: Wesierska K, editor. Fluency disorders: theory and practice. Katowice, Poland: Wydawnictwo Uniwersytetu Ślaskiego w Katowicach; 2015. p. 89-99.

7. Przepiórka A, Błachnio A, St Louis KO, Wozniak T. Public attitudes toward stuttering in Poland. International Journal of Language and Communication Disorders. 2013;48:703-714.

8. St Louis KO, Sønsterud H, Carlo EJ, Heitmann RR, Kvenseth H. Public attitudes toward - and identification of - cluttering and stuttering in Norway and Puerto Rico. Journal of Fluency Disorders. 2014;42:21-34.

9. Valente ARS, St Louis KO, Leahy M, Hall A, Jesus L. A countrywide probability sample of public attitudes toward stuttering in Portugal. Journal of Fluency Disorders. 2017;52:37-52.

10. St Louis KO, editor. Stuttering meets stereotype, stigma, and discrimination: an overview of attitude research. Morgantown, WV: West Virginia University Press; 2015.

11. St Louis KO, Sønsterud H, Junuzović-Žunić L, Tomaiuoli D, Del Gado F, Caparelli E, et al. Public attitudes toward stuttering in Europe: within-country and between-country comparisons. Journal of Communication Disorders. 2016;62:115-130.

12. Weidner ME, St Louis KO. The public opinion survey of human attributes - Stuttering/Child (POSHA-S/Child). Morgantown, WV: Populore; 2014.

13. St Louis KO, Weidner ME, Mancini TM. Comparing parents' and young children's attitudes toward stuttering. Journal of Speech Pathology and Therapy. 2016;1:1-10.

14. Weidner ME, St Louis KO, Glover HL. Changing nonstuttering preschool children's stuttering attitudes. American Journal of Speech-Language Pathology. 2018;27:1-13.

15. Abrams D, Rutland A. The development of subjective group dynamics. In: Levy S, Killen M, editors. Intergroup attitudes and rela- tions in childhood through adulthood. Oxford, UK: Oxford University Press; 2008.

16. Weidner ME, St Louis KO, Burgess ME, LeMasters SN. Attitudes toward stuttering of nonstuttering preschool and kindergarten children: a comparison using a standard instrument prototype. Journal of Fluency Disorders. 2015;44:74-87.

17. Ambrose NG, Yairi E. The development of awareness of stuttering in preschool-children. Journal of Fluency Disorders. 1994;19:229245.

18. Ezrati-Vinacour R, Platzky R, Yairi E. The young child's awareness of stuttering-like disfluency. Journal of Speech Language and Hearing Research. 2001;44:368-380.

19. Langevin M, Packman A, Onslow M. Peer responses to stuttering in the preschool setting. American Journal of Speech-Language Pathology. 2009;18:264-276.

20. Weidner ME, St Louis KO, Nakıscı E, Özdemir RS. A comparison of attitudes towards stuttering of non-stuttering preschoolers in the United States and Turkey. South African Journal of Communication Disorders. 2017;64:1-11.

21. Özdemir RS, St Louis KO, Topbas, S. Stuttering attitudes among Turkish family generations and neighbors from representative samples. Journal of Fluency Disorders. 2011;36:318-333.

22. Glover HL, St Louis KO, Weidner ME. Comparing stuttering attitudes of preschool through 5 th grade children and their parents in a predominately rural Appalachian sample. Journal of Fluency Disorders. 2019;59:64-79.

23. Agency for Statistics of Bosnia and Herzegovina. Bosna i Hercegovina u brojevima 2017 [Bosnia and Herzegovina in Numbers 2017].

24. Schuman MA. Nations in Transition: Bosnia and Herzegovina. New York, NY: Facts on File, Inc.; 2004.

25. Biscevic I, Zecic S, Mujkanovic E, Mujkanovic E, \& Memisevic H. Obstacles to inclusion-Perceptions of teachers from Bosnia and Herzegovina/Inkliuzinio ugdymo igyvendinimo kliūtys: Bosnijos ir Hercegovinos mokytojų nuostatos. Special Education/Specialusis Ugdymas. 2017;1:49-76.

26. St. Louis KO. Research and development for a public attitude instrument for stuttering. Journal of Communication Disorders. 2012;45:129-146.

27. St Louis KO, Weidner ME. Test-retest reliability of the POSHA-S/ Child in 4-11 year old schoolchildren. Canadian Journal of Speech-Language Pathology and Audiology. 2018;42:41-54.

28. St Louis, KO, Myers LE, Barnes MF, Saunders MA, Hall BM, Weidner, M. E. Oral face-to-face versus online administration of the POSHA-S/Child. Perspectives of the ASHA Special Interest Groups. 2019;4:1337-1343.

29. Weidner ME. InterACT Program. Morgantown, WV. Morgantown, WV: MC Speech Books; 2015. 
Appendix A. POSHA-S/Child means for all items, components, subscores, and Overall Stuttering Score (OSS) for 186 children from Kindergarten through sixth grade (Columns 1-4) and all children combined (Column 5) as well as POSHA-S means for all 186 parent (Column 6)

\begin{tabular}{|c|c|c|c|c|c|c|}
\hline POSHA-S/Child means & Kindergarten & 1st \& 2nd grades & 3rd \& 4th grades & 5th $\& 6$ th grades & Children all & Parents all \\
\hline Column & 1 & 2 & 3 & 4 & 5 & 6 \\
\hline Overall stuttering score & -6 & -2 & 9 & 19 & 3 & 26 \\
\hline Beliefs: about children who stutter & 11 & 14 & 26 & 34 & 19 & 35 \\
\hline Traits/personality & -16 & -5 & 6 & 30 & 1 & 39 \\
\hline Blame (at fault) ${ }^{\mathrm{a}}$ & 8 & 52 & 89 & 89 & 53 & 62 \\
\hline Nervous $^{\mathrm{a}}$ & -7 & -7 & 9 & 0 & -2 & 77 \\
\hline Shy ${ }^{\mathrm{a}}$ & -24 & -9 & -56 & 9 & -20 & -23 \\
\hline Something bad ${ }^{a}$ & -2 & 17 & 52 & 74 & 30 & - \\
\hline Can talk well & -57 & -78 & -65 & -20 & -57 & - \\
\hline Help from & 12 & 17 & 24 & 27 & 19 & -1 \\
\hline SLP & 70 & 83 & 100 & 90 & 84 & 98 \\
\hline Stutterers & 5 & 12 & -14 & -11 & -1 & -47 \\
\hline Parent & 43 & 61 & 89 & 90 & 67 & - \\
\hline Doctor $^{\mathrm{a}}$ & -70 & -87 & -78 & -62 & -74 & -52 \\
\hline Cause & -6 & -17 & 7 & -4 & -6 & 30 \\
\hline Genetic & 3 & -19 & -60 & -29 & -22 & 6 \\
\hline Learning $^{a}$ & -32 & -42 & -9 & 6 & -23 & 74 \\
\hline Something bad ${ }^{a}$ & -38 & -14 & 3 & -32 & -22 & - \\
\hline Fright $^{a}$ & - & - & - & - & - & -56 \\
\hline Act of god ${ }^{a}$ & 12 & 11 & 12 & 0 & 9 & 10 \\
\hline Virus/disease (germs) & 14 & 0 & 68 & 50 & 28 & 54 \\
\hline Ghost/demon/spirit (invisible) & 5 & -40 & 26 & -21 & -8 & 94 \\
\hline Potential & 54 & 60 & 68 & 82 & 64 & 72 \\
\hline Make friends & 87 & 78 & 100 & 85 & 87 & 100 \\
\hline Normal life (do same things as others) & 22 & 52 & 33 & 75 & 43 & 98 \\
\hline Do any job (any job as adult) & 50 & 65 & 68 & 88 & 65 & 51 \\
\hline Job requiring good judgment (can make good choices) & 58 & 45 & 71 & 83 & 62 & 40 \\
\hline Self Reactions: to children who stutter & -23 & -18 & -8 & 4 & -13 & 17 \\
\hline Accommodating/helping & 5 & 34 & 47 & 60 & 33 & 54 \\
\hline Ignore & 15 & 78 & 79 & 85 & 59 & 96 \\
\hline Me (I should help) & 7 & 64 & 49 & 35 & 35 & -36 \\
\hline Finish words ${ }^{a}$ & -19 & -22 & 15 & 45 & 1 & 57 \\
\hline Say "slow down"a & -41 & 4 & -6 & 32 & -7 & 20 \\
\hline Joke (laugh) ${ }^{\mathrm{a}}$ & 64 & 83 & 100 & 85 & 81 & 88 \\
\hline Hide $^{a}$ & 2 & -2 & 46 & 79 & 26 & 96 \\
\hline Social distance/sympathy & 10 & -14 & 6 & 28 & 7 & 35 \\
\hline Comfortable (fun to play with) & 60 & 51 & 87 & 73 & 65 & 88 \\
\hline Bothered $^{a}$ & 38 & 65 & 85 & 95 & 67 & \\
\hline Pity (feel sorry for them) ${ }^{a}$ & $15^{b}$ & $78^{b}$ & $89^{b}$ & $67^{\mathrm{b}}$ & $57^{b}$ & 82 \\
\hline Impatient ${ }^{\mathrm{a}}$ & - & - & - & - & - & 96 \\
\hline Patient & 43 & 96 & 95 & 90 & 77 & - \\
\hline Doctor $^{\mathrm{a}}$ & 18 & -61 & 5 & 30 & -2 & 72 \\
\hline
\end{tabular}


Appendix A. Continued

\begin{tabular}{|c|c|c|c|c|c|c|}
\hline POSHA-S/Child means & Kindergarten & 1st $\& 2$ nd grades & 3 rd $\&$ 4th grades & 5 th $\& 6$ th grades & Children all & Parents all \\
\hline Teacher $^{\mathrm{a}}$ & 3 & -74 & -57 & -20 & -33 & - \\
\hline Neighbor $^{\mathrm{a}}$ & -3 & -52 & -24 & 35 & -12 & 68 \\
\hline Friend $^{\mathrm{a}}$ & -18 & -78 & -59 & -13 & -41 & - \\
\hline Parent $^{\mathrm{a}}$ & -13 & -78 & -84 & -26 & -47 & - \\
\hline Brother or sister ${ }^{\mathrm{a}}$ & -21 & -78 & -56 & -3 & -38 & -22 \\
\hline Myselfa & -15 & -65 & -74 & -49 & -47 & -33 \\
\hline Preference & 19 & 31 & 65 & 58 & 40 & - \\
\hline Impression & - & - & - & - & - & 26 \\
\hline Want to stutter & - & - & - & - & - & -59 \\
\hline Knowledge/experience (experience) & -85 & -73 & -78 & -76 & -79 & -42 \\
\hline Amount known & - & - & - & - & - & -9 \\
\hline Persons known & - & - & - & - & - & -88 \\
\hline Source: personal & - & - & - & - & - & -27 \\
\hline Informant & -95 & -96 & -91 & -93 & -94 & - \\
\hline Child & -77 & -55 & -69 & -62 & -67 & - \\
\hline Knowledge source & - & - & - & - & - & 20 \\
\hline TV/radio & - & - & - & - & - & 40 \\
\hline Print & - & - & - & - & - & 38 \\
\hline Internet & - & - & - & - & - & 31 \\
\hline School & - & - & - & - & - & 8 \\
\hline Specialists & - & - & - & - & - & -17 \\
\hline Obesity/wheelchair & -41 & -38 & -44 & -37 & -40 & -14 \\
\hline Preference & -9 & -16 & -30 & -29 & -20 & - \\
\hline Obesity & -14 & -7 & 17 & 32 & 4 & - \\
\hline Wheelchair & -4 & -25 & -77 & -89 & -43 & - \\
\hline Experience & -74 & -60 & -57 & -46 & -61 & - \\
\hline Obesity & -55 & -38 & -25 & -19 & -37 & - \\
\hline Wheelchair & -92 & -81 & -90 & -72 & -85 & - \\
\hline Impression & - & - & - & - & - & 22 \\
\hline Obese & - & - & - & - & - & 3 \\
\hline Wheelchair & - & - & - & - & - & 41 \\
\hline Want/have & - & - & - & - & - & -71 \\
\hline Obese & - & - & - & - & - & -72 \\
\hline Wheelchair & - & - & - & - & - & -70 \\
\hline Amount known & - & - & - & - & - & 6 \\
\hline Obese & - & - & - & - & - & 14 \\
\hline Wheelchair & - & - & - & - & - & -2 \\
\hline
\end{tabular}

aMean ratings inverted so that higher scores reflect more accurate, sensitive attitudes; "Ratings for "Pity (Feel sorry for)" are not inverted for the POSHA-S/ Child because feeling pity is regarded as a positive attitude for young children. 